\title{
DIE GROOT SINODE VAN DORDRECHT 1618
}

\author{
PROF. DR. A. D. PONT
}

Op 13 November 1618 het die Jaaste nasionale sinode onder die eerste kerkregtelike bedeling van die Nederlandse kerk, in die oudste stad in die provinsie Holland, naamlik Dordrecht byeengekom. Terselfdertyd het hierdie Sinode, venweë die aanwesigheid en deelname van so 'n groot getal buitelandse teoloë, ook die karakter gedra van 'n gereformeerde ekumeniese konsilie. Die eerste èn laaste derglike byeenkoms van Calvinistiese Kerke en teoloë in die reformatoriese en onmiddellike nareformatoriese tyd. Hierdie sinode was nie alleen belangrik vanweë sy samestelling nie maar veral vanweë die werk wat deur die sinode gedoen is. Die leerstellige arbeid van hierdie sinode wat bekend staan as Die Dordtse Leerreëls het nie alleen die derde Belydenisskrif van die $\mathrm{N}$ derlandse Kerk geword nie, maar het ook tot vandag toe Belydenisskrif van ons Kerk gebly. Miskien mag bygevoeg word dat die Dordtse Leerreëls miskien die onbekendste Belydenisskrif van ons Kerk is, maar dit beteken nog nie dat dit daarom 'n onbekende Belydenisskrif is nie. Merkwaardig genoeg is juis daardie teologiese standpunte en insigte wat by Dordrecht ter sake was, vandag in die kerklike en teologiese wêreld weer besonder aktueel en sal 'n behoorlike kennis van die beslissings wat by Dordrecht gevel is, van besondere waarde wees vir ons Kerk waar ons predikante, ook vanweë hulle ondertekening van die proponentsformule, gebonde is aan daardie uitsprake.

Dit is ook interessant om daarop te let dat die beslissings van die Sinode van Dordrecht, behalwe in die eerste eeu na die aanvaarding daarvan, nooit besonder populêr was nie. Van die kant van die teenstanders van Die Dordtse Leerreëls is alles in die werk gestel om die indruk te bestendig dat die waarhede wat in die Leerreëls geformuleer word, „omstrede" sou wees dit wil sê: nie heeltemal aanvaarbaar vir 'n normale en beskaafde mens nie. Opmerklik was dan ook dat in die vorige eeu in Nederland toe ds. N. Scholsman sy „Eerezvil ter gedachtenis van de voor tweehonderd jaren te Dordrecht gehoudene Nationale Synode" in 1819 gepubliseer het, dit in die verligte en oudliberale kringe 'n storm van verontwaardiging ontlok het en dat daar selfs stemme opgegaan het dat die kerklike tug teen hom ingespan moes word. Daarnaas het ook die eenling, dr. H. F. Kohlbrügge 1803-1875, sy bedenkings ten opsigte van die leer van Dordrecht gehad omdat dit na sy mening die aksent verskuif 
van die uitverkiesende God na die uitverkore mens. Oor die algemeen gesproke was die waardering vir die resultate van die Dordtse Sinode in die teologiese wêreld van die vorige eeu niè hoog nie. Die uitsondering was die "Gereformeerde gezindte” in Nederland waarvan ' $n$ woordvoerder hom by die 300 -jarige herdenking van die Sinode as volg uitgelaat het:

„Zy (d.i. die Sinode van Dordrecht) neemt daarom een centrale plaats in in de Geschiedenis der Nederlandsche Gereformeerde Kerk. Door hare vijanden is $\mathrm{Zy}$ gesmaad, gelasterd, gevloekt, maar de Christenen die leefden uit Gods Woord, naar de beginselen door Calvijn vertolkt, hebben met eerbied en dankbaarheid teruggezien op die glorieuze Kerkvergadering, die zoo kostelijk de leer van Gods souvereine genade heeft beleden en gehandhaaft."

Sou mens moet ooreel na die heersende teologiese rigting op die breë terrein van die kerk dan sou mens moet oordeel dat ook in ons tyd, 350 jaar na die opening van die groot Sinode van Dordrecht, die waardering vir die resultate daarvan nie besonder hoog sal wees nie. Immers ook in ons tyd waar die vrysinnigheid die heersende teologiese opvattings sterk kleur, waar die humanistiese sosialisme die populêre filosofie van die tyd geword het, kan daar vir die werk van die Dordtse vadere nie veel waardering wees nie juis omdat die Sinode dààrdie opvattings verwerp wat vandag so algemeen aanvaar word.

As 'n mens die historiese agtergronde van die Dordtse Sinode nagaan, dan blyk dat die stryd wat daar besleg is, eintlik van die begin van die kerkhervormingsbeweging in Nederland, in die kiem aanwesig was en word dit duidelik dat die stryd wat in 1618-1619 by Dordrecht kerklik afgesluit word, byna onafwendbaar genoem moet word.

Met die opkoms van die kerkhervorming in Nederland het verskillende reformatoriese strominge in Nederland hulle invloed laat geld. Hoewel die Lutheranisme die oudste stroming was, het dit relatief die minste invloed uitgeoefen. Daarnaas het die Wederdoperdom wat vir 'n tydlank 'n magtige volksbeweging was, egter self 'n groot deel van sy invloed verspeel toe die radikale vleuel in allerlei wandade verval. Hoewel die Doperdom 'n belangrike rol speel, het dit nooit werklik 'n algemene houvas op die Nederlandse volk gekry nie. Die derde stroming wat dan vermelding verdien, is diè wat deur Lindeboom aangedui word as die nasionaal-gereformeerde rigting. Aanvanklik was hierdie groep ook bekend as die Sakramentariërs vanweë die afkeer wat hulle gehad het in die Roomse mis. Hierdie rigting wat ouer 
was as die Calvinisme in Nederland het verskillende vooraanstaande woordvoerders gehad, en het oor die algemeen die klem gelê op 'n Bybelse vroomheid en daarby op die suiwerheid van leer en lewe. Hierdie groep het tot op sekere hoogte aansluiting gevind by Desiderius Erasmus, 1469-1536, die beroemde humanis, en het voorstanders geword van 'n Bybelse humanisme waar dit gaan om suiwere kennis van die Bybel en eenvoudige vroomheid van die hart. Hierdie rigting, so stel Lindeboom dit, sien die opdrag van die Christendom om ,niets anders te doen dan dit algemeen-menschelijke, natuurrechtelijke gegeven in ieder mensch tot ontwikkeling te brengen, het Godskind bewust te maken van den band, die hem aan den Vader bindt" . . . Voor dogma was in deze beschouwingwyze weinig plaats evenmin voor eenig exclusivisme; sy was oecumenisch, katoliek ingesteld." Hierdie rigting wat in Nederland wortel geskiet en gebloei het, het in die breëre reformatoriese stroom buite Nederland veral sy aansluiting by Huldrych Zwingli, 1484-1531, die Duitssprekende hervormer van Zürich, gevind.

Hierdie nasionaal-gereformeerde rigting het sy standpunt baie duidelik na vore gebring en daar kan gewys word op die geskrif van Hendrik van Bommel Oeconomica Christiana van 1523 ,op die persoon van Hinne Rode van Utrecht wat later predikant in Oos-Friesland was maar vanweë sy Zwingliaanse opvattings in 1530 afgesit is, op Gulielmus Gnapheus wat in 1531 sy Een troost ende spieghel der siecken laat verskyn; en nog verskillende ander. Meer bekende figure is die pastoor van Heemvliet, Angelus Merula, 1482-1557; die voormalige pastoor van Alkmaar, Cornelis Cooltuyn, wat bekend geword het vanweë sy Het Evangelie der Armen; en daarnaas ook Marten Micron, een van die eerste voorgangers van die Nederlandse vlugtelinggemeente in Londen, wat in 1552 sy Van hot Nachtmaal Christi ende van de Misse uitgegee het. In hierdie beweging is seker cen van die belangrikste figure die hervormer van Gelderland, Johannes Anastasius Veluanus, wat in Nederland groot invloed uitgeoefen het deur sy werk Der Leken Wechwyser van 1554 . Opmerklik is veral sy skerp verwerping van die leer van die uitverkiesing wat hy sien as 'n leer wat in teenspraak is met die liefde van God en verskillende tipies-humanistiese eksentsverskuiwings kan by hom gekonstateer word. Aksentverskuiwings wat sy teologiese denke sterk antroposentries kleur. In dieselfde beweging moet ook nog verwys word na Dirk Coornhert 1522-1590, wat 'n merkwaardige posisie inneem insover dat hy, nadat hy hom van die Roomse kerk losgemaak het, nooit weer kans gesien het om hom by die Hervormde kerk aan te 
sluit nie. Hoewel hy sy indiwidualistiese standpunt onverkort handhaaf, het hy tog in die kringe van die Nasionaal-gereformeerde rigting groot invloed uitgeoefen, veral deur sy skerp bestryding van die leer van die erfsonde en die uitverkiesing. Opmerklik is ook dat Calvyn en die calvinisties-reformatoriese teologie voortdurend deur hom skerp aangeval is. Inderwaarheid was Coornhert meer 'n Stoisynse humanis as 'n teoloog, maar sy belang lê daarin dat sy gedagtes verreikende invloed gehad het.

Kenmerkend van hierdie nasionaal-gereformeerde rigting was dat dit dogmaties nie presies omlyn was nie, maar dat dit nieteenstaande daardie gebrek, tog 'n groot mate van homogeniteit gehad het. Dit was teen hierdie Nasionaal-gereformeerde rigting wat die opkomende Calvinisme die stryd moes voer, 'n stryd wat eers deur die Sinode van Dordrecht in 1618-1619 besleg is.

Die Calvinisme het in Nederland sy invloed eers laat geld vanaf die veertigerjare van die sestiende eeu en die Institusie word die eerste maal opgeneem in die Index van verbode boeke in 1546, hoewel die oudste nederlandse vertaling eers uit 1560 dateer. Hoewel dit onduidelik is hoe die Calvinisme presies in Nederland geplant is, is dit wel duidelik dat die Calvinisme deur besonder bekwame, begaafde en toegewyde manne in Nederland verbrei is. Hier kan gedink word aan manne soos Guido de Bres, 1522-1567, wat in 1561 die Nederlandse Geloofsbelydenis opgestel het en wat in 1567 as martelaar te Valenciennes opgehang is. Daarnaas Pieter Hazaert, 'n Vlaming van geboorte, wat as oortuigde Calvinis groot werk gedoen het totdat sy dood in 1579 'n einde gemaak het aan sy rustelose swerwersbestaan terwille van die verbreiding van die evangelie. Dan was daar Casper van der Heyden 1530-1586 wat saam met Petrus Datheen beskou kan word as een van die ywerigste en invloedrykste verbreiders van die gereformeerde leer in Nederland. Meeste van hierdie manne was in meerdere of mindere mate leerlinge, vriende en medewerkers van Calvyn en het deur hulle invloed die calvinisme in Nederland nie alleen geplant nie maar dit ook die geleentheid gegee om die ander rigtings in die Nederlandse kerklike wêreld te oorwoeker. Die groot faktor wat baie bydra tot die vordering van die Calvinisme is nie alleen die kwaliteit van die predikante nie maar ook die hegte kerklike organisasie wat van meet af gebou word. Soos Lindeboom dit stel: „, . . . de kerkvaderen der calvinistische kruisgemeenten, de consistories. Zij bestuurden de gemeenten en vertegenwoordigde ze naar buiten, voerden onderlinge correspondentie, en een dicht net van connecties, informaties, aanbevelingen, steunverleeningen is ... tusschen de 
gemeenten gespannen. Kerkelijk gemeenschapsbesef, gevoelens van roeping en heilige verplichting gingen zoodoende samen met zakelijke oorwegingen van steun en versterking, ... daarby uitte zich een groote offergezindheid. Hierdie Calvinisme was dan ook die enigste hervormingsbeweging wat instaat was om die Roomse kerk in die Nederlandse gemeenskap te vervang en na die Convent van Wesel 1968 en die Sinode van Emden 1571, het die Calvinisme al sterker op die voorgrond getree. Soos die Nederlandse geweste geleidelik bevry word van die Spaanse juk, word die eise van heropbou en organisasie al belangriker. Die Calvinistiese predikante het dan ook geywer vir 'n goeie kerklike orde, 'n deeglike en verantwoorde Bybelse leerstelsel en die sorgsame uitoefening van die tug.

Al voortgaande kristalliseer daar egter twee groot strydvrae wat binne die kerk self verdeeldheid bring tussen die calvinistiese predikante enersyds en die woordvoerders van die nasionaalgereformeerde rigting. Die strydvrae kan aangedui word as:

i. die vraag na die Kerkorde en Belydenis van die kerk; en

ii. die vraag na die verhouding tussen die Owerheid en die Kerk.

Hierdie twee vrae en die stryd om die antwoorde daarop te vind, is eintlik die agtergrond van die Sinode van Dordrecht. Die strydende partye wat ook deur hulle beginselstandpunt van mekaar geskei was, was enersyds die min of meer oorheersende calvinistiese party was, in dogmaticis die leer van die uitverkiesing as die cor ecclesiae vooropgestel het terwyl hulle terselfdertyd die vryheid en -onafhanklikheid van die kerk ten opsigte van die owerheid baie sterk beklemtoon het. Die leidinggewende figure in hierdie rigting was Franciscus Gomarus, 1563-1641, wat vanaf 1594 professor te Leiden was; ds. Festus Hommius 1576-1642; ds. Johannes Bogerman 1576-1637, een van die grootste kanselredenaars van sy tyd en 'n erkende gesaghebbende op die gebied van die Semitiese tale; ds. Petrus Plancius, 15521622 , een van die bekendste calvinistiese predikante van Amsterdam.

Aan die ander kant was daar die nasionaal-gereformeerde rigting wat ook aangedui is as die rekkelijke party wat in besonder as leier gehad het prof. Jacobus Arminius, 1560-1609, wat hoewel hy nog te Genève by Calvyn se opvolger Theodorus Beza lesings volg, reeds as predikant te Amsterdam onder verdenking was omdat hy die suiwere Calvinistiese leer weerspreek het. Toe Arminius in 1603 professor te Leiden word, het hy sy gedagtes ook begin oordra op sy studente. Arminius se opvatting was dat die belydenisskrif as gesaghebbende omskrywing van 
die inhoud van die geloof van die $k=r k$, liewer moet verdwyn. Hy wou in sy onderwys die Heilige Skrif uitlê en niè gebind deur die uitspraak van die kerklik-aanvaarde belydenisskrif nie. Daarby het Arminius geen kwaad daarin gesien dat die owerheid in kerklike sake 'n belangrike rol sou speel nie en het hom ook uitgelaat teen die hele teokratiese ideaal soos dit in art. 36 van die Nederlandse Geloofsbelydenis omskrywe word. Uiteraard het hièrdie opvattings stryd uitgelok en in die stryd is die rekkelijke partij algaande gekonsolideer agter Arminius, en na sy dood agter sy opvolger prof. Simon Episcopius en die hofprediker ds. Johannes Uyttenbogaert, 1557-1644.

Die stryd het aan die Universiteit van Leiden ontstaan waar Arminius in 1604 professor geword het. Hoewel hy by sy benoeming beloof het dat hy sy afwykende gevoelens nóg op die preekstoel, nóg aan die universiteit sou voordra, het hy hom nie daaraan gehou nie en sy gedagtes ook aan die teologiese studente oorgedra. Dit het daartoe gelei dat hy in botsing gekom het met sy kollega prof. Franciscus Gomarus, 'n teoloog van uitstaande bekwaamheid wat met groot skerpsinnigheid Arminius se afwykings raakgesien en in die openbaar weerlê het. Die stryd tussen Arminius en Gomarus aan die universiteit te Leiden was nie alleen heftig nie maar het ook die kerk in beroering gebring. Lank het die stryd tussen die twee hoogleraars nie geduur nie, want in 1609 is Arminius aan tering oorlede terwyl Gomarus kort daarna 'n beroep as predikant te Middelburg aanvaar het. Dit het die twiste egter niè beëindig nie, omdat 'n breë kring van vereerders en leerlinge van Arminius laasgenoemde se gedagtes verder uitgedra het. In Arminius se plek is sy leerling Simon Episcopius, 1583-1643, aangestel wat reeds as student „suspect in de leere was, omdat hij Arminij discipel, Ende soogkint geweest hadde;" terwyl Johannes Polyander, 'n vredeliewende calvinis, in Gomarus se plek aangestel is.

Die volgelinge van Arminius wat afgewyk het van die leer van die kerk het g-leidelik onder die leiding van Uyttenbogaert 'n eie party binne die kerk gevorm en hulle gevoelens oor die leer in 1610 in 'n dokument, 'n Remonstrantie, saamgevat wat aan die provinsiale state van Holland voorgelê is. As gevolg van hierdie optrede het hulle die naam Remonstrante gekry. In 1611 volg dan die Contra-Remonstrantie van die Calviniste. Hoewel van die kant van die owerheid verskillende pogings aangewend is om in hierdie geskil te bemiddel, het dit niè geslaag nie en in 1614 gaan die owerheid selfs so ver om 'n Resolutie tot den vrede der Kercke uit te vaardig waardeur die owerheid feitlik bepaal dat daar leervryheid in die kerk moet 
wees en dat die belydenisskrifte niè gesaghebbend in die kerk moet geld nie. Dit het meegebring dat die Calviniste nou sterker begin vra het dat die owerheid sy toestemming moes verleen dat daar 'n Nasionale Sinode gehou kon word om die leerverskil uit te praat èn op te los. Maar omdat verskillende hoë owerheidspersone simpatiek teenoor die Arminiane gestaan het wat 'n minderheidsgroep in die kerk was, het die versoek om 'n Nasionale Sinode te hou, voorlopig op dowe ore geval. Deurdat die owerheidsbemoeiing die geskil al verder laat vorder het, het dit uiteindelik op sommige plekke ook gelei tot skeuring in die kerk. Die Remonstrante het hulleself verenig in dolerende kerke omdat hulle by die owerheid gekla het dat hulle posisie bemoeilik is.

Die hele saak het egter 'n gunstige wending vir die calviniste geneem toe die stadhouer, Prins Maurits, in 1617 openlik vir die calviniste kant gekies het. Maar die hoogste regeringsliggaam, die State-Generaal, was nog verdeel oor die kwessie van die saamroep van 'n Nasionale Sinode omdat die verteenwoordigers van die verskillende provinsies nie eengesind was nie - Die provinsie Holland, Utrecht en Overijssel het die byeenroep van 'n Nasionale Sinode teengestaan omdat hulle tereg bevrees was dat die Remonstrante hulle saak op 'n Nasionale Sinode sou verloor. Hoewel Prins Maurits persoonlik propaganda gemaak het vir die hou van 'n Nasionale Sinode, kon hy die provinsies Holland en Utrecht nie oortuig nie. Uiteindelik het hy met 'n staatsgreep die provinsiale state van Holland en Utrecht afgedank en daarná sò hersaamgestel dat die besware teen die hou van 'n Nasionale Sinode weggeval het. Terselfdertyd is Johan van Oldenbarneveldt 1547-1619, die raadspensionaris van die Provinsiale State van Holland, gevange geneem en in 1619 weens hoogverraad tereggestel. Daarmee het die invloedrykste owerheidssteun vir die Remonstrante ook weggeval en was dit duidelik dat die Remonstrante die hele stryd feitlik klaar verloor het.

Na die ingrype van prins Maurits was die pad ge-effen vir die hou van 'n Nasionale Sinode. Vanweë die feit dat die hele twis ook in die buiteland weerklank gevind het, is van die begin af besluit om ook geleerde teoloë uit die buiteland te nooi om die Sinode by te woon èn daaraan deel te neem. Die buitelandse teoloë het uit verskillende afvaardigings bestaan. Uit die Anglikaanse Kerk was daar vier man onder leiding van George Carleton 1559-1628, die biskop van Llandaft, wat beskryf is as „a bitter enemy to the papists and a severe Calvinist". Biskop Carleton was ook die nie-amptelike leier van die groep buite- 
landse teoloë. Saam met hierdie groep is daar ook dr. Walter Balcaugval uit Skotland, hoewel hy vanuit Engeland na die Sinode gekom het. Die teenwoordigheid van so 'n sterk afvaardiging uit Engeland hang saam met die feit dat die koning Jakobus I van Engeland 'n besondere belangstelling vir die hele leerkwessie gehad het en dit was ook koning Jakobus wat voor die aanvang van die Sinode reeds gestel het dat die Sinode in sy beraadslagings gelei moet word deur die Woord van God en daarby ,the general consent of the ancient church and councels, and approved doctors thereof, before the time of the church's defection to popery". 'n Ander interessante figuur op die Sinode is die puritein Guildemus Amesius 1576-1633, wat as sekretaris van die sinodale voorsitter opgetree het. Nadat hy in 1610 na Nederland gevlug het uit Engeland vanweë sy verset teen die biskoplike regering van die Engelse kerk, het hy later professor aan die Illustere School te Franeker geword, vanwaar hy 'n groot invloed op die Nederlandse teologiese denke uitgeoefen het. Hoewel die Franse kerk uitgenooi was om ook na Dortrecht te kom en daar ook reeds 'n afvaardiging benoem is, het die Roomse koning van Frankryk hulle belet om die Sinode by te woon. Tog het ds. Pierre du Moulin, 1568-1658, nog tydens die Sinode 'n lang geskrif gestuur waarin hy tot die slotsom kom: "Derhalwe verdoeme ic Arminium ende zijnen aenhanck."

Uit die Duitse gebied, die Paltz, waarmee die Nederlandse Kerk nóu verbonde was, het drie afgevaardigdes gekom, naamlik die professore Scultetus, Tossanus en Altingius waarvan Scultetus genoem kan word as een van die beroemdste teoloë van sy tyd.

Uit Hessen het 'n viertal teoloë gekom - onder hulle was prof. Rudolphus Glocenius, 'n geniale teoloog wat soveel wetenskaplike publikasies die lig laat sien het dat hy later self nie eers meer al sy eie werke geken het nie.

Uit Switserland het die stad Zürich vir Johann Jacob Breytinger afgevaardig, die opvolger van die beroemde Heinrich Bullinger. Uit die stad Basel het 'n tweetal teoloë gekom, terwyl ook Bern en Schafthausen elk 'n afgevaardigde gestuur het. Uit Genève, die stad van Calvyn, het die geleerde Jean Diodati gekom wat reeds op 19-jarige leeftyd tot doktor in die teologie gepromoveer het, en op 21-jarige leeftyd professor in Hebreeus geword het. Nie alleen was hy 'n alom-beroemde kanselredenaar nie, maar studente van dwarsoor Europa het na Genève gegaan om sy lesings te volg. Geen wonder dat hy een van die leidinggewende figure op die Sinode was nie. Uit die Duitse stad Bremen het 'n drietal teoloë gekom, maar aangesien hulle mèèr 
Luthers as Calvinisties ingestel was, het hulle nie 'n groot bydrae op die Sinode gelew $\in \mathrm{r}$ nie. Uit Emden, die stad in Duitsland waar die eerste Nasionale Sinode van die Nederlandse Kerke onder die kruis gehou is, hct daar 'n tweetal predikante gekom, uit Nassau òò 'n tweetal terwyl die afvaardiging uit Brandenburg nie opgedaag het nie.

Hierdie buitelandse afgevaardigdes was nie alleen volle lede van die Sinode nie, maar ten opsigte van die leer het hulle selfs 'n beslissende stem gehad.

Uit die Nederlandse Kerk sèlf het ook 'n groot aantal voortreflike teoloë die Sinode van Dordrecht bygewoon. Die grootste onder hulle was ongetwyfeld Johannes Bogerman wat ook as voorsitter van die Sinode opgetree het. Hy was nie alleen 'n uitmuntende teoloog nie, maar op 42-jarige leeftyd, toe die Sinode plaasgevind het, in die krag van sy lewe. As voorsitter het hy die vergadering op uiters bekwame wyse gelei en 'n groot bydrae tot die welslae daarvan gelewer.

Dan was daar die twee skribas: Festus Hommius, 'n buitengewoon groot geleerde, voorbeeldig in sy ywer en toewyding; naas hom Sebastiaan Damman. As assessore het opgetree ds. Rolandus van Amsterdam en ds. Hermanus Faukelius van Middelburg, die opsteller van die alombekende Kort Begrip wat tot vandag toe, in sy verwerkte vorm, by ons gebruik word. Dan was daar ook Gisbertus Voetius, toe nog maar 29 jaar oud, wat later as professor te Utrecht in 'n beroemde hoogleraar sou ontplooi. Ds. Jacobus Trigland, èèn van die vurigste calviniste op die Sinode, het die twyfelagtige eer gehad dat hy een van die lelikste mense, wat sy uiterlik betref, daar was.

Aangesien die voertaal van die sinode Latyn was terwille van die buitelanders, was daar nie baie ouderling-afgevaardigdes nie - slegs ' $n$ vyftal het die Sinode bygewoon. Uit die Franssprekende deel van die Nederlandse Kerk was daar vier predikante en twee ouderlinge terwyl ook 'n aantal professore die vergadering bygewoon het. Johannes Polyander van Leiden, Sibrandes Libbertus van Franeker wat bekend was vanweë sy kwasterigheid, Antonius Thysius van Hardewijk, terwyl Franciscus Gomarus wat toe te Groningen professor was, daardie universiteit verteenwoordig het. Die vyfde professor is Antonius Walaeus. 'n Agtiental politieke kommissarisse wat namens die State-Generaal sitting geneem het, het die lys van sinodelede volgemaak.

Nadat die Sinode plegtig geopen en gekonstitueer is, is die ampsdraers verkies en toe besluit dat die vyf artikels wat deur 
die Remonstrante opgestel is, die basis van die bespreking sou vorm. Nadat besluit is om 'n aantal van die Remonstrante op te roep om hulle opvattings persoonlik te kom toelig, het die Sinode eers met ander sake voortgegaan, totdat die Remonstrante in Dordrecht aangekom het. Vroeg in Desember het die 12 Remonstrantse predikante onder leiding van prof. Episcopius van Leiden, in die sinodale vergadering verskyn. Dààr word hulle mcegedeel dat hulle hulle opvatting kan voorlê, uitlê en verdedig, maar dat hulle moet begryp dat hulle voor die Sinode verskyn soos voor 'n regter wat uiteindelik hulle leer sal beoordeel.

Wanneer die Remonstrante uiteindelik voor die Sinode verskyn, hou Episcopius 'n lang rede waarin hy 'n uiteensetting gee van sy standpunt en ook nie nalaat nie om skimpend te verwys na Prins Maurits en die optrede van sommige calvinistiese woordvoerders. Sy rede vat hy in drie punte saam nl.

1. dat hulle gekant is teen die harde en afgryslike gevoelens omtrent die predestinasieleer soos deur sommige calviniste uitgespreek is;

2. dat hulle gekant is teen diegene wat skeurings in die Kerk veroorsaak het en

3. dat hulle die Christelike owerheid graag 'n seggenskap in leerkwessies in die kerk toeken.

Met hierdie rede het Episcopius ook duidelik verklaar dat die Remonstrante nie sal afwyk van hulle standpunt nie en ook die oordeel van die Sinode nie vrees nie.

'n Merkwaardige insident ontstaan as die Sinode van Episcopius 'n afskrif van sy rede vra en hy eers die indruk skep dat sy rede onleesbaar is en dan uiteindelik tog 'n afskrif inlewer. Maar as dit blyk dat die geskrewe stuk nie ooreenkom met sy gesproke rede nie, blyk dit verder dat Episcopius nog 'n tweede kopie het wat weer verskil van die ingelewerde stuk. Hoewel dit alles nie baie belangrik was nie, skep dit die indruk dat Episcopius nie eerlik optree nie.

Met die volgende verskyning van die Remonstrante voor die Sinode, lê hulle 'n lang en uitvoerige aanval op die Sinodeleer voor waarin hulle nie alleen die Sinodelede as "skeurmakers" beskuldig nie maar ook as "uitvinders van nieuwigheden". Daarby het hulle die wettigheid van die Sinode so skerp as moontlik aangeval. Met hierdie optrede het die Remonstrante byna alle simpatie verspeel. As die Remonstrante die volgende dag weer verskyn en hulle gevra word om nou hulle standpunt uiteen te sit, begin hulle eers weer met 'n aanval op die Sinode en stel dat die Sinodelede maar een party in die kerk verteenwoordig en daarom nie as regters oor hulle kan sit nie. Ook 
word 'n heftige aanval op die voorsitter, ds. Bogerman, gemaak. Daarom dien hulle ' $n$ formele protes tecn die Sinode in.

Die Sinode, en veral die buitelandse teoloë, het hierdie optrede taamlik skerp veroordeel ook omdat die Remonstrante se bewerings so duidelik uit die lug gegryp was. Daarom is die Remonstrante hieroor ook duidelik tereggewys.

Daarna is oor die opvattings van die Remonstrante gehandel maar hier het die Remonstrante getrag om nie oor hulle eie opvattings te praat nie, maar om 'n wig te dryf tussen die verskillende groepe in die Sinode. Telkemale wanneer hulle na hulle eie opvattings gevra is, het hulle weggekruip agter die ekskuus dat hulle gewete hulle dit nie toelaat nie en probeer om die handelinge te vertraag en uit te rek. Dit was in hierdie verband wat prof. Glocerius van die Remonstrante gesê het: „Hulle is canonici irregulares; hulle wil nie as ongehoorsaam beskou word nie, en tog is hulle nie gehoorsaam nie". Dit was duidelik dat die Remonstrante hulle nie wou onderwerp aan die orde van die Sinode nie en dat hulle eintlik 'n behoorlike ondersoek na hulle opvattings wou vermy. Geleidelik word dit duidelik dat met hierdie „hardquastige Campioenen", soos hulle deur Leydekker genoem is, nie gepraat kan word nie. Tog gaan die Sinode dag vir dag met eiendelose geduld met hulle in debat, sonder dat die saak self vordering kon toon.

Uiteiendelik, op 14 Januarie 1619, raak die Voorsitter, Ds. Bogerman, se geduld op en in plaas daarvan dat hy die besluit van die Sinode om die Remonstante weg te stuur aan hulle voorlees, het hy aan hulle gestel dat hulle voortgaan om die Sinode as 'n teëparty te beskou in plaas van regter. „U het”, so het die voorsitter betoog, "teenoor die opregtheid, vriendelikheid en sagmoedigheid van die Sinode bedrog, lis en leuens gestel. Met bedrog en leuens het $u$ begin, met bedrog en leuens eindig $u$. Met hierdie lof sal u nou weggestuur word. God wat die harte ondersoek, sien ook u bedoelings, maar ken ook die opregtheid van die Sinode. God weet, met watter geduld ons op u gehoorsaamheid gewag het en hoe ons tot Hom gebid het vir u. Maar al $u$ handelinge was steeds vol bedrog. Daarom is u die oorsaak dat ons die handelinge wat begin is, nie kan voortsit nie en daarom word u uit die Sinode weggestuur. Die Sinode sal aan die hele christenheid bekendmaak dat dit aan die Sinode nie aan geestelike wapens ontbreek om $u$ hardnekkigheid te straf nie. Die hele Christenheid sal die billikheid van die sensuur oor $u$ nog eenmaal erken." Jacobus Trigland het dertig jaar nà die beeindiging van die Sinode die gebeure so beskryf: met die platkant van sy oophande na hulle uitgestrek, het hy (dit is ds. Bo- 
german, die voorsitter) sy laaste woord gespreek: Ite! dit is: U het met leuens begin, $u$ het met leuens geeindig: Gaan heen! Dit het ek met skrik en gemoedsontsetting gehoor en gesien, so dat ek nou nog met ontsteltenis daaraan dink".

Eers na die wegstuur van die Remonstrante kon die Sinode werklik vordering maak. Daar is toe noukeurig ingegaan op die Vyf Artikels van die Remontrante en die is volledig besreek. Veral die bewysplase uit die Heilige Skrif waarop sowel die Remonstrante as die Calviniste hulle beroep het, is besonder noulettend bespreek. Die teologiese diskussies tussen die teoloë van faam is deurentyds gevolg deur 'n groot groep toeskouers wat altyd toegang tot die handelinge van die Sinode gehad het.

$\mathrm{Na}$ hierdie besprekings het die voorsitter begin om die opvatting van die Sinode te formuleer na aanleiding van die volstandige bespreking en die skriftelike uiteensetting wat deur die verskillende afvaardigings opgestel is. Eers op 23 April was die uiteensetting, dieVyf Leerreels van Dordrecht, opgestel, goedgekeur en deur elke Sinodelid onderteken.

Daarna het die Sinode ook nog die Nederlandse Geloosfbelydenis en die Heidelbergse Kategismus bespreek. Ten opsigte van die belydenis het die buitelandse teoloë hulle wens gestel dat die kerk in Nederland standvastig by hierdie regsinnige, vrome en eenvoudige belydenis sou volhard, dit ongeskonde aan die nageslag sou oorlewer en dit tot aan die koms van Jesus Christus sou bewaar. Oor die kategismus is geoordeel dat dit nêrens in stryd met die Heilige Skrif was nie en nie verander hoef te word nie.

'n Oordeel oor die Remonstrante is ook opgestel, naamlik dat hulle invaerders van nuwighede in die leer was, versteurders van die kerk en dat die leringe wat hulle verkondig het van die Woord van God en die Belydenisskrifte afwyk. Daarby het hulle hulle hardnekkig teen die Sinode en die owerheid gedra. Daarom word hulle uit hulle kerklike ampte geskors tot hulle tot inkeer kom en berou oor hulle dade toon.

Uiteindelik was die handelinge van die Sinode ten einde. Op 6 Mei 1619 is in 'n plegtige byeenkoms in die groot kerk in Dordrecht die Vyf Leerreëls van Dordrecht afgekondig. Ds. Bogerman het die verrigtinge met 'n lang en vroom gebed geopen en daarna het Ds. Sebastiaan Damman die Voorrede tot die leerreëls gelees. Daarna is eers 'n kollekte vir die armes gehou en toe het Ds. Damman voortgegaan om te lees. Toe sy stem vermoeid geraak het, het Ds. Festus Hommius verder gelees. Daarna is die naam van elke ondertekenaar gelees en by die hoor van sy naam 
het elkeen, by wyse van instemming, sy hoed afgehaal. Nadat die oordeel oor die Remonstrante ook gelees is, het Ds. Bogerman die verrigtinge afgesluit met 'n dankgebed.

$\mathrm{Na}$ hierdie gebeure en nadat die nodige pligplegings afgehandel is, het die buitelandse afgevaardigdes vertrek en het die afgevaardigdes van die Nederlandse Kerk nog voortgegaan met werk ten behoewe van die nasionale kerk totdat op $29 \mathrm{Mei}$ ook die werksaamhede afgehandel was sodat die Sinode na „solemnele dancksegginghe tot God" kon sluit.

As gevolg van die besluite van die Sinode is ongeveer 200 predikante afgesit terwyl ongeveer 80 uit die land verban is. 'n Sewentigtal het die Acte van Stilstand geteken waardeur hulle vrywillig uit hulle amp getree het en onderneem het om hulle te onthou van deelname aan kerklike twiste. 'n Veertigtal predikante het egter tot ander insigte gekom en die Formuliere van Enigheid onderteken en is daarop in hulle amp herstel.

Dit is merkwaardig hoe verskillend die opvattings oor hierdie Sinode is. Enersyds kom dit vanweë die feit dat die Remonstrante en die liberale teologie wat hulle voorgestaan het, wel op die Sinode veroordeel is, maar hulle is nie oortuig van die calvinistiese beginsels wat daar her-beklemtoon is nie. Vandaar dat die Dordtse Sinode tot vandag toe nog veroordeel en afgeafgewys word. Ook in ons dae waar die handhawing van die suiwere leer niè meer belangrik geag word nie, waar die Skrif, volgens vele, maar uitgelê moet word volgens die eie, persoonlike insig of willekeur, sal 'n herdenking van die werksaamhede van hierdie Sinode nie welkom wees nie. Maar dit moet ook gestel word dat die Remontrante, wat geweier het om eerlik en openhartig hulle saak voor die Sinode te stel, asof hulle sèlf nie hulle saak vertrou het nie, baie daartoe bygedra het dat die Sinode van Dordrecht uiteindelik moes optree soos hy opgetree het. Daarby is die leier van die Remonstrante, prof. Episcopius, ook nie vry te pleit van onbeskaamde en hooghartige optrede nie. Hoewel hy sy minagting vir die voorsitter, wat maar 'n predikant was, nie kon wegsteek nie, kan met reg betoog word dat „die eennvoudige dominee" Bogerman in alle opsigte Episcopius se meerdere was. Daarby was dit ook so dat die Remonstrante met 'n nuwe leer" na vore gekom het en die Sinode het die volste reg gehad om hierdie leer, waaraan die Remonstrante so hardnekkig vasgehou het, te beoordeel en soos dit nodig geblyk het, te veroordeel.

Of die Vyf Leerreëls van Dordrecht in alle opsigte die korrekte antwoord was op àl die probleme wat deur die Sinde be- 
handel is, is ' $n$ totaal ander saak. Die feit is egter dat daardie Leerreëls nou al vir 350 jaar as 'n Belydenisskrif van die Nederlandse Kerk en dus ook van òns Kerk geld. As hierdie Belydenisskrif onbekend en dikwels ongelees is, dan is dit nie 'n tekortkoming van die Dordtse vadere nie, maar van die huidige geslag. Interessant bly dit egter dat dit ook die laaste uitspraak oor die leer in die vorm van 'n Belydenisskrif is van die Nederlandse Kerk èn ook van die Afrikaanse Kerke. Dit wil dus te kenne gee dat die Vyf Leerreëls van Dordrecht oral, altyd en deur almal in die Kerk aanvaar en geglo is.

Daarby kan daarop gewys word dat die Sinode van Dordrecht ook op ander vlakke werk van meer as blywende waarde verrig het. Allereers kan genoem word die opdrag tot vertaling van die Bybel, die sg. „Statenvertaling” wat in 1637 gereed gekom het. Aan hierdie Bybelvertaling wat ook vir die Afrikanervolk van groot waarde was, het wat die Ou Testament betref $F$. Bogerman, W. Baudartius en G. Bucerus die werk gedoen terwyl die vertalers van die Nuwe Testament J. Rolandus, F. Hommius en A. Walaeus was. Hierdie vertaling van groot verdienste is in ons Kerk gebruik tot in 1933 toe dit deur dieAfrikaanse vertaling vervang is.

Verder het die Sinode op die vlak van die kerklike orde ook werk van blywende waarde verrig en hierdie Sinode het byvoorbseld die formule van ondertekening waarmee alle aankomende predikante in die kerk hulleself bind om die Heilige Skrif volgens die samevatting van die geloof van die kerk, soos dit in die belydenisskrifte voorkom, te leer, definitief omskrywe en geldig maak. Daarmee is aan die belydenisskrif ' $n$ duidelike en omskrewe plek in die lewe van die kerk toegeken.

Uiteindelik staan en val die waarde van die Sinode egter op die leerstellige vlak. As die herdenking van hierdie beroemde en eerbiedwaardige Sinode, wat die leerstellige gevoelens van die calvinistiese kerke van Europa aan die begin van die sewentiende eeu weergee, daartoe kan bydra dat ons kerklike belydenisskrif die Vyf Leerreëls van Dordrecht, mèèr op die voorgrond tree, dan sal op diè wyse die werk en toewyding èn geloof van hierdie manne andermaal geëer word. 